\title{
Contemporary Trends Regarding Knowledge And Practices Of Dental Implants Among Dental Interns Working In Educational Institutes Of Karachi, Pakistan
}

\author{
Muhammad Farhan Khan, Fatima Naseem A Khan, Irfan Ali, Muhammad Rashid Ahmed, \\ Rubab Jawed, Qurratulain Zahoor
}

ABSTRACT:

Aim: The aim of this study was to assess the information about dental implants among dental interns and to relate their perception of future dental implant practice.

Study Design and Setting: A cross-sectional study was conducted on dental interns of various dental teaching colleges of Karachi including public and private institutions.

Methodology: The instrument used was a self-administered, structured, closed-ended questionnaire which was modified measuring tool for the dental interns' knowledge and perception towards implant dentistry. The data collected from the study was analyzed using SPSS.

Results: Two hundred and seventy dental interns of 5 different colleges of Karachi filled a questionnaire about the knowledge and future perception of dental implant practice in general dentistry. It was observed that majority of the dental interns $44.2 \%$ did not have adequate knowledge of dental implant and $87.6 \%$ encourage to improving the undergraduate syllabus of dental implants.

Conclusion: This study showed limited knowledge and awareness about dental implants among dental interns, but they highly encouraged in improving the curriculum of dental implants at undergraduate level.

Key Words: Dental implants, Dental Interns, Implant Dentistry.

\section{INTRODUCTION:}

Implant dentistry is one of a kind in having the capacity to accomplish the dental objectives. ${ }^{1}$ The replacement of dental implants in the restoration of mostly partially and complete edentulous jaws have turned into an entrenched and accepted contemporary clinical strategy because of its predictability. ${ }^{2}$ Dental practice has encountered astounding change in dental materials of restoration, management and planning of cases that are typically viable for the better prognosis of tooth misfortune. ${ }^{3}$ Scientifically driven methodologies have been

\begin{tabular}{|c|}
\hline $\begin{array}{l}\text { Muhammad Farhan Khan } \\
\text { Associate Professor, HOD Prosthodontic Department } \\
\text { Baqai Medical University }\end{array}$ \\
\hline $\begin{array}{l}\text { Fatima Naseem A Khan } \\
\text { Registrar, Oral \& Maxillofacial Surgery Department } \\
\text { Baqai Medical University } \\
\text { Email: fnaknlm@gmail.com }\end{array}$ \\
\hline $\begin{array}{l}\text { Irfan Ali } \\
\text { Associate Professor, HOD Oral \& Maxillofacial Surgery } \\
\text { Department, Baqai Medical University }\end{array}$ \\
\hline $\begin{array}{l}\text { Muhammad Rashid Ahmed } \\
\text { Professor, HOD Anatomy, } \\
\text { Baqai Medical University }\end{array}$ \\
\hline $\begin{array}{l}\text { Rubab Jawed } \\
\text { Assistant Professor, Research \& Development Department } \\
\text { Baqai Medical University }\end{array}$ \\
\hline $\begin{array}{l}\text { Qurratulain Zahoor } \\
\text { Registrar, Oral \& Maxillofacial Surgery Department } \\
\text { Baqai Medical University }\end{array}$ \\
\hline $\begin{array}{l}\text { Received: 02-08-2019 } \\
\text { Accepted: 25-11-2019 }\end{array}$ \\
\hline
\end{tabular}

developed that give the patients' esthetically and functionally great alternatives for teeth replacement. ${ }^{4}$ The partially edentulous patient is would now able to experience substitution of a single tooth or a few missing teeth with implant retained crowns that give a similar feel they had with their natural teeth. ${ }^{5}$ Using implant retained removable prostheses in complete edentulous patient increase the confidence than that conventional complete denture wearers normally experience. ${ }^{6}$ In a study, it was found that selfconfidence increased in $88 \%$ of patients after implant treatment and $98 \%$ stated that their oral health had improved ${ }^{7}$. This success and satisfaction of dental implants ${ }^{8}$ in turn results in a widespread use of dental implants within the dental professional community ${ }^{9}$. The restoration of dental implants is thought to be as a specialist technique for oral health care that was practiced by implantologists only and required preparation beyond the regular dental school educational programs. ${ }^{10}$ However, despite the fact that implant dentistry has separated field of specialty, it remains a complex subject requiring a sound establishment to gain competence in this field. ${ }^{11}$ Literature review, recommended that most patients seek their dental specialists to give them information and treatment in regard to dental implants. ${ }^{12}$ These undergraduates are presented to the theoretical information behind the act of dental implant just as a possibility for tooth substitution so they can advise patients of their treatment options. ${ }^{13}$ However, implant practice should be included in undergraduate program to acquaint the essential practice with maturing general dentist. Awareness amongst the undergraduate medical/dental students concerning any new update in their field will be beneficial in educating the 
general population. Undergraduate students are considered the ambassadors of the specialty. ${ }^{14} \mathrm{~A}$ baseline data related to the prosthodontics practices among practicing dentists in any population is critically important. From knowledge through indexed literature there are no studies that report the trends in prosthodontic practices among GDPs in a Pakistani population. Such data is vital for understanding the current patterns in practice of GDP and for planning of widespread oral health care for the population ${ }^{15}$

The aim was to assess the knowledge of dental implants among dental house officers and to relate their perception of future practice of implants.

\section{METHODOLOGY:}

A cross-sectional study was conducted on dental interns of various colleges of Karachi including public and private institutions. Ethical clearance was obtained from the Ethics Committee of Baqai Medical University. Approximately 900 dental interns are recruited every year in 14 dental colleges of Karachi. The sample size was calculated by sample size formula $n=\left[\mathrm{DEFF}^{*} \mathrm{~Np}(1-\mathrm{p})\right] /\left[\left(\mathrm{d}^{2} / \mathrm{Z}^{2}{ }_{1-\mathrm{a} / 2} *(\mathrm{~N}-\right.\right.$ 1) $\left.+p^{*}(1-p)\right]$ at $95 \%$ confidence interval, where, $Z$ á $/ 2=$ $1.96, \mathrm{p}=50 \%$ sample proportion and $\mathrm{d}=5 \%$ of precision error was takenand sample size obtained was 270 . According to sample size of five dental colleges; 3 colleges from private pool and 2 from public dental colleges' pool were chosen. Written consent was obtained from study participants after explaining in detail about the study. The instrument used was a self administered, structured, closed ended questionnaire which was modified for the dental interns' perception, and knowledge towards implant dentistry. The content validity for the questionnaire was analyzed as per the procedures given by Lawshe ${ }^{16}$. Content validity of the questionnaire was measured by taking the opinion of 5 subject experts, and the questionnaire was modified accordingly. If any question had a content validity ratio of $<0.99$, the question was deemed as inadequate and was deleted or changed after consultation with the experts. After the validity assessment, out of 12 original questions, 5 were retained without any change, 3 were modified, and 4 were deleted. The modified questionnaire consisted of 8 items. Part A comprised of four questions related to the knowledge of dental interns toward implantology. Part B comprised of 4 questions related to perception of dental implant practice. All the interns of the 2018-2019 batch were briefed about the study. Only those interns or house officers were included who had done the rotation of restorative dentistry departments. Those who consented filled up the questionnaire of about 10 minutes. Descriptive analysis was performed by calculating the frequencies and percentages. The analysis was performed using the Statistical Package for the Social Sciences version 20.

\section{RESULT:}

Total of 275 participated in the study, out of which 67 were gathered from Dow Dental College, 72 were from Karachi Medical \& Dental College, 53 were Liaquat Medical \& Dental College, 34 from Ziauddin University and 49 from Baqai Medical University. Out of which $44.2 \%$ had moderate knowledge of dental implants, $46 \%$ choose implants as choice of replacement because of long lasting treatment option, and most of the participants that is $64.6 \%$ thought case selection is the prime factor of better prognostic results. While $43.3 \%$ thought its frequency as treatment option could be hinder by its cost. In response to attitude, half of the participants $51.8 \%$ agreed that implant dentistry was the part of the BDS curriculum but about $87.6 \%$ thought to expand the syllabus of applied dental implant. Most participants $70.4 \%$ preferred to train in tailored implant course during their house job period to improve their practice of dental implant and 53.5\% also liked to learn from the certificate course during their house job. $87.7 \%$ did not experience any dental implant patients in their training period.

\section{DISCUSSION:}

This study was carried in four different dental college hospitals where internees were posted for their clinical rotation. This study assesses the knowledge and perception of interns towards implants and their perception to use it in future practice. They all studied local council approved curriculum, which includes the basic information of implant dentistry in restorative subjects of undergraduate course. Implant has been the frontline of dental practice over the past decades. ${ }^{17}$ With spread of awareness and success rate of implants, patients prefer it as the best treatment option. In our study, participants were not confident enough about their basic dental implant knowledge. Implant treatment is a chosen procedure by patient in most treatment cases ${ }^{18}$ so complete information on implant and alternative treatment options must be explained to the patient so that they can make an educated decision. ${ }^{19} \mathrm{~A}$ study on the Austrian population found that dentists are the primary source of patient information on dental implants followed by friends and acquaintances, print media, and general dentist. ${ }^{20}$ Health workers are an integral part of the health profession and therefore, the poor knowledge of dental implant (9.7\%) recorded among them in this study could be as a result of lack of practice of dental implantology by dentists in their hospitals. ${ }^{21}$ Other study showed an average, 80 out of 110 General dental practitioners had basic knowledge about implant dentistry and $65.5 \%$ were not aware about advance surgical procedures like sinus lift, guided bone regeneration etc., for dental implant surgery. ${ }^{22}$ Only 9 (6.3\%) interns perceived that they were well prepared in replacing the teeth with implants. ${ }^{23}$ In an other study, $39.11 \%$ of the dental interns were very confident regarding the knowledge of implant procedures. The interns were little confident regarding the additional surgical procedure (23\%), elevating the flap $(13 \%)$, and suturing of gums (28\%) in implant procedure. ${ }^{24}$ 
Table 1: Veriable regarding knowledge of dental implant

Responses

\begin{tabular}{|c|l|}
\hline How do you evaluate your knowledge regarding dental implant? & \\
a) Adequate & $81(29.3 \%)$ \\
b) Moderate & $73(44.2 \%)$ \\
c) Insufficient & \\
\hline Why do you prefer dental implant as replacement choice of treatment? & $22(8 \%)$ \\
a) Aesthetics & $120(43.6 \%)$ \\
b) Conservative (does not required reduction of abutment teeth) & $127(46.1 \%)$ \\
c) Long lasting & $6(2.1 \%)$ \\
d) Don't know & \\
\hline What is the most important factor for successful prognosis of implant treatment? & $178(64.7 \%)$ \\
a) Selection of case & $5(1.8 \%)$ \\
b) Type and materials of implant & $27(9.8 \%)$ \\
c) Compliance of patients & $32(11.6 \%)$ \\
d) Surgical technique & $26(9.45 \%)$ \\
e) Operator's personal experience & $7(2.5 \%)$ \\
f) Don't know & \\
\hline Which of the following reason affect the popularity of dental implant? & $119(43.2 \%)$ \\
a) Expensive & $86(31.2 \%)$ \\
b) Invasive procedure & $70(25.5 \%)$ \\
c) Lack of awareness & \\
\hline From which course might you want to get training on dental implant? & $147(53.4 \%)$ \\
a) Continuing dental education of 2-3 days' workshop & $62(22.5 \%)$ \\
b) Extensive certificate courses of months or one year & \\
c) Fellowship programs & \\
d) MSc programs & \\
\hline
\end{tabular}

Graph I: Questions on perception of future practice of dental implant

Have you done any implant case or assists in your internship period?

Did you suggest adding more information about implant dentistry in BDS curriculum?

Were implant treatment procedure included in your BDS curriculum?

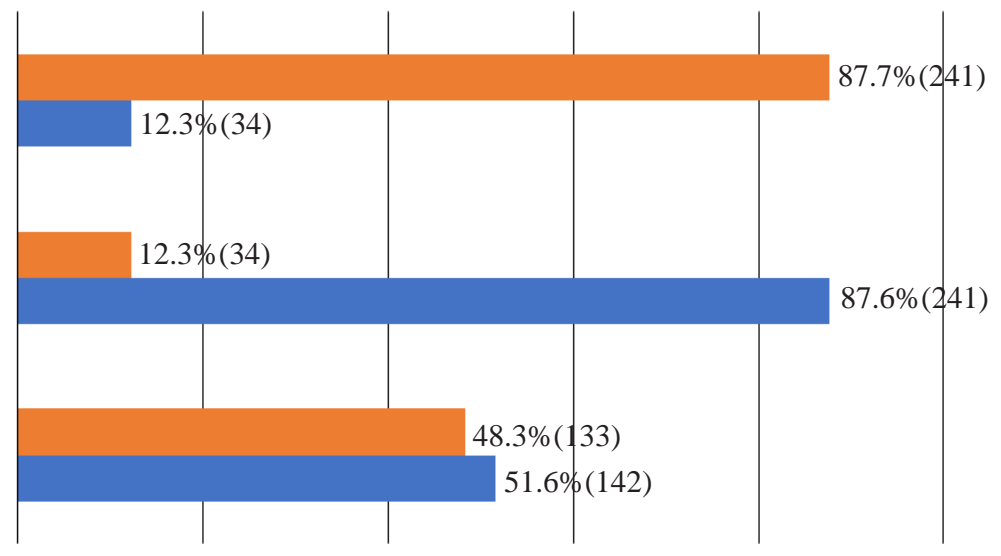

The awareness found was less in this study as compared to above mentioned studies which may be because of low level of education and the study was conducted in teaching hospital where most of the patients were from rural community. ${ }^{25}$ However, in our study $46.1 \%$ said they will choose implant because it retained longer than other options. The study of another population about advantages of dental implants, $55.4 \%$ reported that the main advantage of dental implants is its conservational dental approach as compared to other fixed prosthesis (FPD). ${ }^{26}$ Upon asking about the reason of rejection by patient to having implant procedure about $43.2 \%$ suggested that cost can highly affect the decision of patients followed by fear of invasive procedure. The other study was conducted regarding public awareness and knowledge of implant revealed that cost was the biggest barrier of implant treatment. ${ }^{6}$ Furthermore in India, dental students were asked about having dental procedure and discovered that $17.2 \%$ of students were refused to have procedure on themselves 
and $31 \%$ of students were confused to having procedure as they were not aware about it. ${ }^{27}$ When asked whethe the course of applied implantology was the part of BDS curriculum, $48.3 \%$ were not even sure and $87.6 \%$ suggested to expand the course of dental implantology in the BDS curriculum. According to Saudi study 50\% of dental students expressed the need of further knowledge on dental implants and $40 \%$ agreed that they did not have enough information regarding the subject. ${ }^{28}$ Another study was undertaken to assess the knowledge of dentists preferring implants as a choice for replacement of missing tooth/teeth, it can be suggested that with the emerging priority of implants in general practice, there is a need to introduce dental implants into dental curriculum. ${ }^{24}$ In this study; regarding acquiring knowledge in the field of implant dentistry $53.4 \%$ choose certificate program, similarly in Barcelona $71 \%$ preferred one-year certificate or modular courses by dental implantologist. ${ }^{29}$ Other study in India showed over $70 \%$ of subjects feel the need to have implant training as a part of their undergraduate clinical curriculum whereas about $56.6 \%$ feel that it should be made into a separate specialty. ${ }^{30}$ In an other Indian study; whopping response of $91.7 \%$ students was revealed as they wanted more information to be added in their BDS course because this will directly affect how well they learn and use implant treatment options in their future dental practice. ${ }^{31}$ However, in this study $87.7 \%$ students diet not have practical experience of dental implant. An, Iraqi study showed positive response regarding observation and assistantship of $5^{\text {th }}$ year students with $55 \%$ in surgical placement of the implant and $73 \%$ students had their practical experience in their college. ${ }^{32}$ Whereas, a study in Nepal showed $90.9 \%$ general dental practitioners were not practicing dental implant in their routine practice due to lack of knowledge and confidence. ${ }^{13}$ In Enugu Nigeria, $7.2 \%$ dental interns preferred dental implants as a choice of treatment. ${ }^{21}$ In North Karnataka India, dental practitioner were asked about dental implant cases in their practice in which $80 \%$ GDP did not practice dental implants, while others referred the cases to specialists. ${ }^{33}$ The future perception of implants is appreciable, but there is need of strengthening education in young dentists to reinforce knowledge and awareness of dental implants in education sectors. The limitations of this study were sample size and limited use of implant supported prosthesis in dental teaching hospitals as compared to private clinics. Currently, there is no hands-on patient based or mannequin-based teaching of dental implants for undergraduates. These students are exposed to the general theory behind the use of dental implants only as an option for tooth replacement so that they are able to inform patients of their treatment options. Hence, within the limitations of our study, we propose that the B.D.S. curriculum be modified appropriately to expose students to dental implants from the diagnostic, treatment planning, surgical, and restorative perspectives.

\section{CONCLUSION:}

This study found that the majority of the dental interns' confidence of future practice about dental implants was constrained due to clinical source of information which has not been attained. Our study found that $87.6 \%$ of dental interns wanted more information to be provided regarding dental implants in their B.D.S. program.

\section{REFERENCES:}

1. Mittal Y, Jindal G, Garg S. Bone manipulation procedures in dental implants. Indian J. Dent. 2016; 7(2):86.

2. Esposito M, Hirsch JM, Lekholm U, Thomsen P. Biological factors contributing to failures of osseointegrated oral implants,(I). Success criteria and epidemiology. Eur J Oral Sci. 1998; 106(1):527-51.

3. Berge TI. Public awareness, information sources and evaluation of oral implant treatment in Norway. ClinOral Implants Res. 2000; 11(5):401-8.

4. Walia K, Belludi SA, Kulkarni P, Darak P, Swamy S. A comparative and a qualitative analysis of patient's motivations, expectations and satisfaction with dental implants. J Clin Diagn Res. 2016;10(4):ZC23.

5. Alnahwi M, Alqarni A, Alqahtani R, Magnas BB, Alshahrani FN. A survey on radiographic prescription practices in dental implant assessment. J Applied Dent Med Sci. 2017;3:148-56.

6. Al Hashim H, Saleh F, Al Essa R, Taher Y, Khalifa M, Al Yaseen D, Ansari SH. Knowledge and Awareness of Dental Implants: A Survey Done among Saudi General Public. Donnish Journal of Dentistry and Oral Hygiene. 2017;3:1926.

7. Grogono AL, Lancaster DM, Finger IM. Dental implants: a survey of patients' attitudes. Journal of Prosthetic Dentistry. 1989; 62: 573-576.

8. Tomruk CO, Özkurt-Kayahan Z, 'ençift K. Patients' knowledge and awareness of dental implants in a Turkish subpopulation. Journal of Advanced Prosthodontics. 2014; 6: 133-137.

9. Berge TI. Public awareness, information sources and evaluation of oral implant treatment in Norway. Clinical oral implants research. 2000;11(5):401-8.

10. Abdulrahman Bin Dawas, et al. "Dental Interns' Awareness Regarding Implant Placement in Medically Compromised Patients". EC Dental Science. 2018; 17(2):63-6.

11. Jivraj S, Corrado P, Chee W. An interdisciplinary approach to treatment planning in implant dentistry. Br Dent $\mathrm{J}$. 2007;202(1):11.

12. Chowdhary R, Mankani N, Chandraker NK. Awareness of dental implants as a treatment choice in urban Indian populations. Int J Oral Maxillofac Implants. 2010;25(2).

13. Haswell M. Dental implants: a different perspective, part one. Implant Practice. 2009;2(1):44-57.

14. Siddiqi KM, Baig MZ, Afzal Z. Awareness Of Dental Implants Among Undergraduate Medical And Dental Students. Pakistan Oral \& Dental Journal. 2017; 37(3):394-7.

15. Rashid H, Naseem M, Dent MR. Prosthodontic services provided by the dental practitioners of Karachi, Pakistan. JPDA. 2014;23(04):159.

16. Taherdoost H. Validity and reliability of the research instrument; how to test the validation of a questionnaire/survey in a research. IJARM 2016; 5(3): 28-36. 
17. Al-Shammari KF, Al-Khabbaz AK, Akar MH, Al-Ansari JM, Wang HL. Implant recommendation as a replacement option after tooth loss for periodontal reasons. Implant dentistry. 2006;15(1):104-10.

18. Zitzmann NU, Sendi P, Marinello CP. An economic evaluation of implant treatment in edentulous patients: preliminary results. Int J Prosthodont. 2005; 18(1):20-7.

19. Guyatt GH, Cook DJ. Health status, quality of life, and the individual. JAMA 1994; 272(8):630-1.

20. Pommer B, Zechner W, Watzak G, Ulm C, Watzek G, Tepper G. Progress and trends in patients' mindset on dental implants. I: level of information, sources of information, and need for patient information. Clin Oral Implants Res. 2011; 22(2):2239.

21. Mgbeokwere U, Okoye L and Ekwueme O. A Survey of the Knowledge of Dental Implants as a Choice in Treatment of Edentulous Jaws among Health Workers in Government Dental Clinics in Enugu. Ann Med Health Sci Res.2011; 1(1):91-5.

22. Dhami B, Shrestha P, Lamichhane B, Sharma AK, Gupta S. Dental Implants and General Dental Practitioners of Nepal: A study of existing knowledge and need for further education.NepJOL. 2017;13(1):212-5.

23. Prabhu S, Joseph John, Saravanan S. Perceived competency towards dental practice among interns of various dental colleges in J Educ Ethics Dent, 2012; 2(1):33-9.

24. M. Srilekha, Ashish R. Jain. Perception and knowledge of dental interns regarding implant procedure for successful prosthodontic treatment. Drug Invention Today 2018; 1(4): 430-2.

25. Supriya M, Amol B, Priya T, Mitali T. A Cross-Sectional Epidemiological Study to Evaluate the Awareness of Patients and Private Dental Practitioners Regarding Dental Implant Therapy in Nashik. J Dent Med Sci 2017; 16(1):22-6.
26. Chaudhary S, Gowda TM, Kumar TA, Mehta DS. Knowledge and attitudes of dental interns in Karnataka state, India, regarding implants.J Dent Educ. 2013 ;77(10):1365-70.

27. Saxena V, Lohiya J, Bhambal A, Vanka S, Talreja N, Kankane N. Out-look of undergraduate dental students on dental implants in Bhopal, Central India. International Journal of Scientific Study. 2014;1(6):2-8.

28. Vohra F, Shah AH, Zafar MS, Kola Z. Knowledge and practice of implant-retained restorations among dental students in Saudi Arabia. Pak J Med Sci. 2015;31(4):848.

29. Sánchez-Garcés MA, Berástegui-Jimeno E, Gay-Escoda C. Knowledge, aptitudes, and preferences in implant dentistry teaching/training among undergraduate dental students at the University of Barcelona. Medicina oral, patologia oral y cirugiabucal. 2017;22(4):e484.

30. Prashanti E, Mohan M. Awareness of dental implants among undergraduate dental students at Mangalore, India. Indian J Appl Res. 2013;3(10):1-2.

31. Chaudhary S, Gowda TM, Kumar TA, Mehta DS. Knowledge, Attitudes, and Perceptions of Undergraduate Dental Students Toward Dental Implants-An All India Survey. Implant dentistry. 2015;24(2):160-5.

32. Al-Radha AS. Effectiveness of teaching dental implant science as merged implant-related lectures on dental student's knowledge. J. int. dent. med. res. 2018;11(1):38-44.

33. Basutkar NA. Assessment of knowledge related to implant dentistry in dental practitioners of north Karnataka region, India. J Dent Implant. 2013;3(1):26. 